\title{
Imaging in the evaluation of renovascular disease
}

\author{
Kjell Tullus • Derek J. Roebuck • Clare A. McLaren • \\ Stephen D. Marks
}

Received: 21 May 2009/Revised: 23 August 2009/Accepted: 24 August 2009 /Published online: 24 October 2009

(C) IPNA 2009

\begin{abstract}
Renovascular disease (RVD) is an important cause of hypertension in children, as it often is amenable to potentially curative treatment. Imaging aimed at finding RVD therefore needs to have high sensitivity so as not to miss important findings. Digital subtraction angiography is the gold standard investigation. Doppler ultrasonography, computed tomography (CT) angiography and magnetic resonance (MR) angiography can all be helpful, but none has, at present, high enough sensitivity to rule out RVD in a child with a suggestion of that diagnosis.
\end{abstract}

Keywords Renovascular hypertension · Imaging ·

Ultrasound · Angiography · Magnetic resonance angiography (MRA) · Computed tomography angiography (CTA) .

Technetium-99m dimercapto-succinic acid

(DMSA) scintigraphy

\section{Introduction}

Renovascular disease (RVD) causes $10 \%$ of hypertension in children $[1,2]$ and is important to be diagnosed, as it may be amenable to treatment [3]. The best investigation for evaluation of RVD is digital subtraction angiography

\footnotetext{
K. Tullus $(\bowtie) \cdot$ S. D. Marks

Department of Paediatric Nephrology,

Great Ormond Street Hospital for Children NHS Trust,

Great Ormond Street,

London WC1N 3JH, UK

e-mail: TulluK@gosh.nhs.uk

D. J. Roebuck · C. A. McLaren

Department of Radiology,

Great Ormond Street Hospital for Children NHS Trust,

London, UK
}

(DSA), which is an invasive procedure with associated risks and is not available in all children's hospitals. Therefore, it must be used with discretion for children. As a result, other modalities of investigating RVD have evolved over the past few years, including magnetic resonance angiography, computed tomography angiography, isotope studies and duplex ultrasonography (US).

The aetiopathogenesis and course of RVD is different between children and adults. The dominating diagnosis in adults is atherosclerosis, mostly affecting the main renal arteries [4]. The diagnostic spectrum is different in children, with the most common reported diagnosis being fibromuscular dysplasia (FMD) [5], although it is unusual for histological confirmation to be obtained and the diagnosis is usually made by exclusion. In some countries, Takayasu's disease is more common than is FMD [6]. Neurofibromatosis type 1 is another common cause of paediatric RVD. The vascular disease in children is often widespread, often with bilateral involvement of the renal arteries and their branches. In a study at our institution we found that, in 33 patients, $16(48 \%)$ had bilateral renal artery stenosis (RAS) and 15 (45\%) had intra-renal disease [7]. Ten (30\%) patients had both bilateral RAS and intra-renal disease. There was mid-aortic involvement in eight (24\%) of these patients, cerebral vascular involvement in seven $(21 \%)$, and mesenteric vessel involvement in ten (30\%). Other parts of the vasculature are also often involved [7]. A study of 21 children (24 stenotic lesions) without co-morbid conditions showed less widespread disease but often involvement of branch arteries: main arteries (six), second-order arteries (12), third-order arteries (three) and accessory arteries (three) [8]. This poses greater demands on the imaging investigations used.

The burden of lifelong antihypertensive treatment and the risks of poorly controlled blood pressure are considerable. As 
renovascular disease is potentially amenable to treatment with various endovascular and surgical techniques, any noninvasive imaging test must have a very high sensitivity, or potentially treatable children will be missed $[9,10]$

In this review we attempted to define the role of these investigations in children with hypertension. However, as there is scanty evidence in the literature to date of using alternative investigations to diagnose RVD in children, we relied on studies of adults and clinical experience in children.

\section{Doppler ultrasonography}

Ultrasound of the abdominal arteries, supplemented with colour and pulsed-wave Doppler examination, is a simple and safe technique [11]. The equipment is widely available, and the procedure is painless and well tolerated by children.

Direct visualisation of RAS is usually not possible in children when greyscale imaging is used, but the renal arteries and their branches can be identified with colour Doppler ultrasound and then interrogated with pulsed-wave Doppler, which produces a real-time trace of flow velocity. Various Doppler parameters may then be used as indirect indicators of RAS $[12,13]$. The peak systolic velocity (PSV) in intra-renal branches of the renal artery is usually reduced distal to a very severe stenosis or occlusion. The acceleration time (the time from the beginning of the systolic upstroke to the highest systolic peak in the waveform) may be increased ( $>70 \mathrm{~ms})$. When the acceleration time is increased and the PSV is low, a characteristic flattened waveform (tardus et parvus phenomenon) is observed. This may be seen unilaterally, distal to a severe RAS, or bilaterally in mid-aortic syndrome (MAS) or coarctation [11, 13, 14]. As in adults, a less severe stenosis of the main renal artery may lead to loss of laminar flow and increased PSV [15], and a ratio of renal-to-aortic velocity greater than 3.0 or 3.5 might also be indicative of RAS [13, 15].

In studies of adults, the sensitivity of US has been found to be less favourable than that of magnetic resonance angiography (MRA) or computed tomography angiography (CTA), with values of $73-85 \%$ and corresponding specificities of $71-92 \%$ (Table 1) $[14,16,17]$. A French study of 22 selected children with hypertension found RVD in 13 children, with two false positive findings and two false negative findings on US [12]. The false negative inves- tigations were in one child with RAS in an accessory renal artery and in one child with bilateral multiple stenosis of distal branches of the renal arteries. The authors concluded that distal stenosis could be missed with US.

A further study of 29 children with renin-mediated hypertension found positive intra-renal US findings in 15 patients and negative findings in 14 . A curative procedure was precluded, due to the severity of the vascular lesions in $67 \%$ (ten of 15 ) of the children with positive US findings while this was possible in $79 \%$ (11 of 14) of those with negative US findings. This emphasises the importance of our performing DSA for all children with the suggestion of RVD despite negative US results (Fig. 1). Its main roles are to assess the condition of children with hypertension but a low clinical probability of RVD, to look for non-vascular causes of hypertension (for example, tumours or renal abnormality) and to measure renal size.

\section{Magnetic resonance angiography}

Contrast-enhanced MRA of the abdominal aorta and renal arteries is performed using gadolinium-based contrast agents and rapid three-dimensional T1-weighted spoiled gradient-recalled echo imaging sequences [18]. Although MRA involves no exposure to ionising radiation, it has certain disadvantages. Many children will need sedation or general anaesthesia. The use of gadolinium-based contrast agents carries some risk of nephrogenic systemic fibrosis in children with impaired renal function, and, in our institution, an estimated glomerular filtration rate (eGFR) of less than $30 \mathrm{ml} / \mathrm{min}$ per $1.73 \mathrm{~m}^{2}$ would be regarded as an absolute contraindication [19]. In most cases children with an eGFR of less than $60 \mathrm{ml} / \mathrm{min}$ per $1.73 \mathrm{~m}^{2}$ should not undergo contrast-enhanced MRA. Despite these reservations, MRA is increasingly used in adults and children and a there are several published studies on its usefulness.

\section{Adult studies of MRA}

A meta-analysis of studies in adult patients published in 2001 showed that few studies had been undertaken and suggested that, although MRA could be used with a high sensitivity to detect clinically important RVD, further research was required [20]. A further meta-analysis in
Table 1 Comparison of US, captopril renography, MRA and CTA compiled mainly from studies of adults in the literature

\begin{tabular}{llll}
\hline Technique & Sensitivity & Specificity & References \\
\hline US & $73-85 \%$ & $71-92 \%$ & {$[14,16,17]$} \\
Captopril renography & $52-93 \%$ & $63-92 \%$ & {$[14,31-36]$} \\
CTA & $64-94 \%$ & $62-97 \%$ & {$[14,16,25,28,29]$} \\
MRA & $64-93 \%$ & $72-97 \%$ & {$[14,16,20-25]$} \\
\hline
\end{tabular}



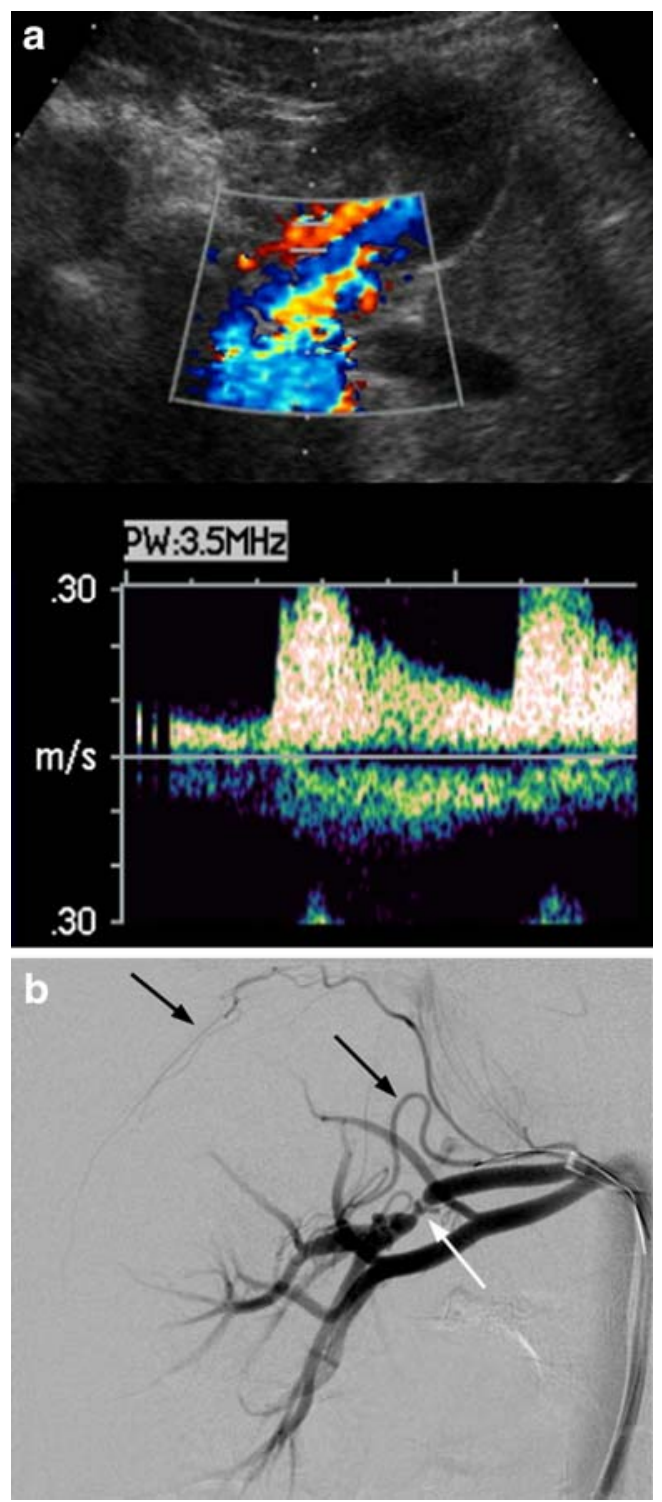

Fig. 1 A 6-year-old boy with hypertension. a Doppler ultrasound of the right renal artery or one of its major branches shows a normal waveform. b Digital subtraction angiography shows a critical stenosis of a large branch of the right renal artery (white arrow), associated with tiny aneurysms. Collateral vessels are seen, both locally and arising from a capsular artery (black arrows)

2002 compiled data from 25 studies of 998 patients, of whom 499 had had non-enhanced MRA and 499 gadolinium-enhanced MRA compared to catheter angiography [21]. The authors found sensitivities of $94 \%$ and $97 \%$ for non-enhanced and gadolinium-enhanced MRA, respectively, with $85 \%$ and $93 \%$ specificity for these methods.

In a further retrospective study of 30 adults evaluated for atherosclerotic RAS with MRA and DSA used as gold standard (where a trans-stenotic gradient of $15 \mathrm{mmHg}$ was regarded as haemodynamically significant), MRAs were independently evaluated by three different radiologists [22].
There were 26 arteries with a significant stenosis of $\geq 60 \%$, and $85-96 \%(22,25$ and 22 , respectively) were correctly identified on MRA by the three radiologists. Accessory arteries are more difficult to be visualised, with MRA identifying only four out of nine, which is potentially relevant to paediatric RVD. The same authors then prospectively compared US, captopril-primed renography, MRA and CT angiography (CTA) in 58 hypertensive patients [14]. MRA showed 93\% sensitivity and 91\% specificity, although further studies of 35 to 60 patients each have shown quite variable sensitivities, ranging from $64 \%$ to $92 \%$ and specificities ranging from $72 \%$ to $96 \%$ $[16,23,24]$.

A large multi-centre study from the Netherlands performed MRA, CTA and DSA in 402 adult hypertensive patients with the suggestion of RAS [25]. Patients were included from six hospitals, and two panels of three observers judged the data. Of the patients, $20 \%$ were found to have clinically relevant RAS, defined as $\geq 50 \%$ stenosis or FMD. The interobserver agreement was found to be only moderate ( $\mathrm{K}$-values 0.40 to 0.51 ), with $62 \%$ sensitivity [confidence interval (CI) $54 \%$ to $71 \%$ ] and $84 \%$ specificity (CI $81 \%$ to $87 \%$ ). Therefore, in this study, MRA was not judged to be sensitive enough to rule out RAS.

\section{MRA in childhood}

There are no published studies comparing MRA with DSA in a useful number of children. Although MRA can, in principle, identify RAS, in our clinical experience we have seen several cases where MRA has over-diagnosed RVD as well as missed severe intra-renal arterial disease (Fig. 2).

In summary, MRA data are still conflicting, with very high sensitivities found in some single-centre studies but with less good performance in larger studies involving several centres. This may be due to centres gaining experience of MRA over time, as well as the limitations of MRA, including poor inter-observer agreements. The main problems of MRA are inadequate spatial resolution, movement artefacts and difficulties when the cause is FMD $[26,27]$. Despite these limitations, which are all particularly relevant in the diagnosis of childhood RVD, new techniques, including quantification of renal blood flow and perfusion imaging, may increase the role of MRA in the future.

\section{Computed tomography angiography}

CTA has recently become more widely used in the diagnosis of RVD, due to improvements in image quality related to multidetector technology (Fig. 3). CTA can be defined as any contrast-enhanced CT technique intended 

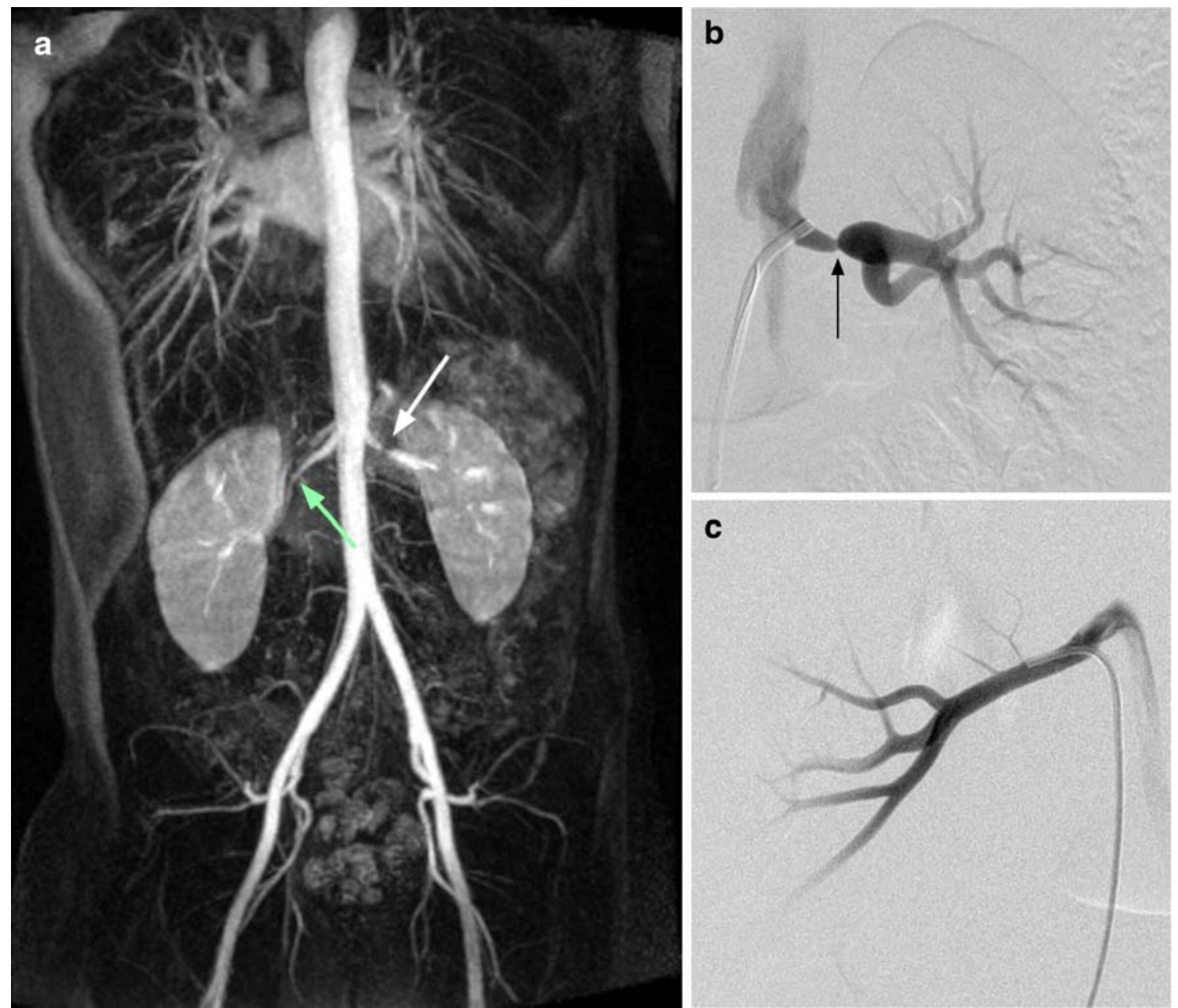

Fig. 2 An 11-year-old boy with hypertension. a Contrast-enhanced magnetic resonance angiography (coronal maximum intensity projection image) shows stenosis of the left renal artery (white arrow) but

specifically to show arterial anatomy [28]. CTA offers better spatial resolution than does MRA, but at the price of the patient's exposure to ionising radiation. Careful attention to technique is essential if the best quality images are to be obtained [28]. The three-dimensional dataset obtained can be manipulated and reviewed as multiplanar twodimensional slices, maximum intensity projections, or as two-dimensional volume-rendered projections (Fig. 3).

A recent study investigated 21 adult patients to identify how well CTA could show main renal arteries, accessory arteries and renal artery FMD [29]. CTA was able to identify all 42 main renal arteries, all 100 accessory arteries and all 40 FMD lesions. Similar results have been found in other studies, with $90-94 \%$ sensitivity and $62-97 \%$ specificity of CTA $[14,16,30]$.

The authors of the large Dutch study mentioned above also included CTA in their evaluation, where images were evaluated by two panels of three investigators [25]. A total of 356 patients was examined by all three modalities (CTA, also suggests stenosis of the right (green arrow). b Angiogram of left kidney confirms a tight stenosis of the left main renal artery (arrow). c The right renal artery is normal

MRA and DSA). Twenty percent of the patients were judged to have clinically relevant RAS. The inter-observer agreement was only moderate ( $\mathrm{K}$-values $0.59-0.64$ ). The sensitivity for CTA in the detection of clinically relevant renal stenosis was $64 \%$ (95\% CI 55-73\%), and the specificity was $92 \%$ (95\% CI 90-95\%).

A retrospective study of 24 children with the suggestion of RVD found RAS in five children, with CTA able to detect four of these [31]. In our clinical experience we find that CTA provides beautiful images of abdominal arteries. This is particularly true in children with mid-aortic syndrome (MAS) and other lesions affecting the large vessels. The ability of CTA to exclude clinically important lesions of small arteries is currently unproven, and, until this is demonstrated, CTA will not be widely applicable to children with suggested RVH. Sedation is often not required, but CTA, like DSA, requires the patient's exposure to ionising radiation, and this is a particularly important consideration in its use for children. 


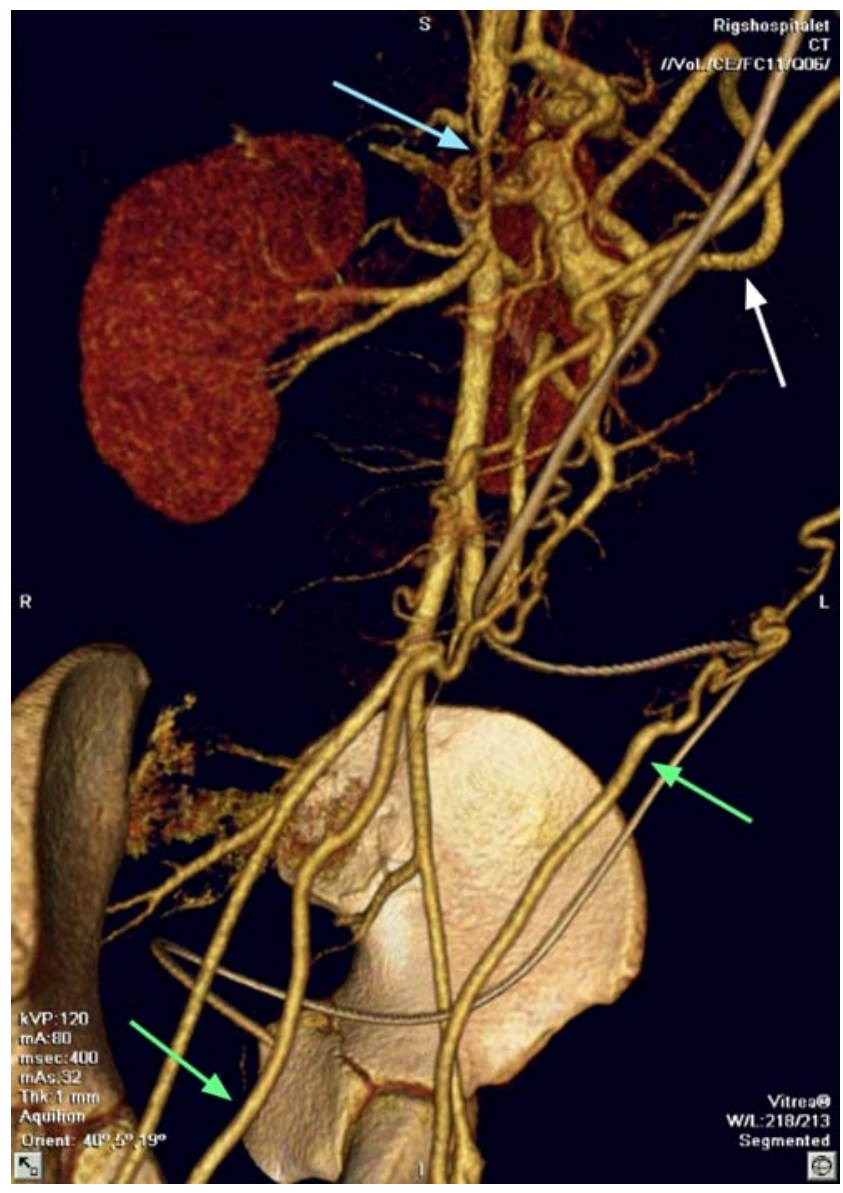

Fig. 3 Two-dimensional ('volume-rendered') representation of a three-dimensional computed tomography dataset from a 12-year-old boy. There is severe stenosis of the abdominal aorta ('mid-aortic syndrome', blue arrow). Enlarged collateral arteries are present: the marginal artery of Drummond (white arrow) connects the superior and inferior mesenteric arteries, and the epigastric arteries (green arrows) connect the subclavian and femoral arteries on each side. Note that, although the coverage is outstanding, detail of the intra-renal arteries is lost

\section{Isotope renography (renal scintigraphy)}

Renal scintigraphy performed before and after administration of an angiotensin-converting enzyme inhibitor (ACEi; usually captopril) is a potential method of localising RAS in children. The usual radiopharmaceuticals used for this purpose are technetium-99m $\left({ }^{99 \mathrm{~m}} \mathrm{Tc}\right)$ dimercapto-succinic acid (DMSA) and ${ }^{99 \mathrm{~m}}$ Tc mercapto-acetyl triglycine (MAG3). For ${ }^{99 \mathrm{~m}} \mathrm{Tc}$ MAG3 scintigraphy the pre- and post-captopril scans are performed on different days, using an activity of $30-110 \mathrm{MBq}$ (scaled according to the patient's mass). Each study takes approximately $40 \mathrm{~min}$, and no sedation is required,

Early reports in adults suggested that captopril scintigraphy was a good screening method, with sensitivities of $83-93 \%$ for the detection of RVD [32-34]. However, the accuracy of this diagnostic test has been poorer in more recent studies in adult patients, with sensitivities of $52-68 \%$ and specificities of $63-92 \%[14,34,35]$.

There is less published experience in children. Reports from our institution have estimated the sensitivities and specificities at $59-73 \%$ and $68-88 \%$, respectively. Some children with potentially treatable RVD were missed on the captopril-primed studies [36, 37]. Studies of 16 children with aorto-arteritis in India showed a sensitivity of $81 \%$ [38], while a study from Chile had a sensitivity of $86 \%$ [39]. A study of 25 children with hypertension found 44\% [11] of children with RVD on DSA, of which nine cases were detected by the isotope study [40]. Although, in principle, it is possible to detect segmental abnormalities with this technique, [41] it is not easy, and we surmise that the high prevalence of bilateral and/or segmental RVD will always limit the utility of ACEi-primed scintigraphy in children. In a recent study from our institution on children, we found a sensitivity of $48 \%$ and a specificity of $73 \%$ for the postcaptopril isotope study to identify correctly children with RVD (submitted for publication).

There have also been suggestions that the captoprilprimed scintigraphy should be able to define those patients that could benefit from an intervention. One large study of 380 patients correctly identified $93 \%$ of those that benefited from an intervention [33]. This finding was later challenged in a Canadian study, where only $58 \%$ were correctly predicted a favourable therapeutic outcome [42].

In summary, captopril-primed isotope studies do not have high enough sensitivity to obviate the need for DSA in children with suggested RVD.

\section{Digital subtraction angiography}

DSA images are created by the subtraction of X-ray data acquired before intra-arterial injection of iodinated contrast material from each of a series of images obtained after injection of contrast medium (Figs. 1 and 2). Rotational angiography is a recent technical development, which allows the generation of threedimensional images. The advantages of DSA are that it currently provides images of the lumens of the renal arteries and their branches with the best spatial and temporal resolution and that it is the platform for endovascular intervention. Various other diagnostic techniques, such as renal vein renin sampling and intravascular ultrasound, may be performed at the same time, when appropriate. There are several disadvantages of DSA. It requires a significantly higher radiation dose than properly performed CTA, it involves a small risk of arterial damage, either at the puncture site or elsewhere, and it only gives indirect information about the arterial 
wall. DSA is usually performed under general anaesthesia in children, especially when endovascular interventions such as angioplasty are planned [43].

\section{Patient selection}

The results of CTA and MRA are improving with time. This is partly due to improved interpretation, but it is due mainly to technical advances. Despite the high-quality images produced, significant RVD (and, especially, intrarenal arterial disease) is still often missed when these modalities are used. Therefore, we would suggest that the best possible images be obtained, using DSA for patients in whom there is a strong suggestion of RVD, such as those with poorly controlled blood pressure on at least two antihypertensive agents and/or those patients with syndromes associated with RVD (such as neurofibromatosis type 1, tuberous sclerosis, Williams' syndrome and Marfan's syndrome) (Table 2) [3].

\section{Summary}

Neither US nor post-captopril isotope renography have high enough sensitivity to exclude treatable RAS as a cause of hypertension in children. Although CTA and MRA produce aesthetically pleasing images of the renal arteries, both will also miss a significant proportion of children with potentially treatable RVD as well as their intra-renal arterial disease (Table 1).

Imaging requirements in hypertension are different for children than for adults, because children's arteries are smaller and the distribution of arterial disease is different. Therefore, our current opinion is that every child with a reasonably strong suggestion of RVD should undergo DSA.

Table 2 Clinical and laboratory signs that indicate an increased chance of renovascular disease [3] (BP blood pressure)

Clinical or laboratory sign

1. Very high BP

2. Secondary symptoms of high BP

- including cerebral symptoms, cardiac failure and facial palsy

3. Hypertension not controlled on $>2$ antihypertensive drugs

4. Diagnosis of a syndrome with a higher risk of vascular disease, such as neurofibromatosis, tuberous sclerosis and Williams' syndrome

5. Signs of vasculitis, in particular Takayasu disease

6. Known or suspected previous vascular insult, such as renal artery thrombosis or umbilical artery catheterisation

7. Bruit heard over the renal artery or arteries

8. Elevated peripheral plasma renin or moderate hypokalaemia

\section{Questions}

(Answers appear following the reference list)

1. What proportion of childhood hypertension is cause by RVD?
a. $1 \%$
b. $2 \%$
c. $10 \%$
d. $25 \%$
e. $50 \%$

2. What is the commonest cause of renovascular hypertension in childhood?
a. Atherosclerosis
b. Fibromuscular dysplasia
c. Mid-aortic syndrome
d. Takayasu's arteritis
e. Trauma

3. Which of the following is not a syndrome associated with RVD?
a. Edward's syndrome
b. Marfan's syndrome
c. Neurofibromatosis type 1
d. Tuberous sclerosis
e. Williams' syndrome

4. What is currently the gold standard investigation in the diagnosis of RVD?
a. CT angiography
b. Digital subtraction angiography
c. Duplex ultrasonography
d. MR angiography
e. Pre- and post-captopril ${ }^{99 \mathrm{~m}} \mathrm{Tc}$ DMSA and ${ }^{99 \mathrm{~m}} \mathrm{Tc}$ MAG-3

5. What are the concerns in the use of gadolinium for MRA in children with RVD and chronic renal impairment?
a. Contrast medium remains in the heart and does not delineate renal vasculature
b. The cost of contrast material
c. Images are of poorer quality due to renal dysfunction
d. The risk of nephrogenic systemic fibrosis
e. Timing of scan has to be prolonged to hours after administration of contrast agent

\section{References}

1. Gill DG, de Mendes CB, Cameron JS, Joseph MC, Ogg CS, Chantler C (1976) Analysis of 100 children with severe and persistent hypertension. Arch Dis Child 51:951-956 
2. Wyszynska T, Cichocka E, Wieteska-Klimczak A, Jobs K, Januszewicz P (1992) A single pediatric center experience with 1025 children with hypertension. Acta Paediatr 81:244-246

3. Tullus K, Brennan E, Hamilton G, Lord R, McLaren CA, Marks SD, Roebuck DJ (2008) Renovascular hypertension in children. Lancet 371:1453-1463

4. Sadowski RH, Falkner B (1996) Hypertension in pediatric patients. Am J Kidney Dis 27:305-315

5. Slovut DP, Olin JW (2004) Fibromuscular dysplasia. N Engl J Med 350:1862-1871

6. McCulloch M, Andronikou S, Goddard E, Sinclair P, Lawrenson J, Mandelstam S, Beningfield SJ, Millar AJ (2003) Angiographic features of 26 children with Takayasu's arteritis. Pediatr Radiol 33:230-235

7. Shroff R, Roebuck DJ, Gordon I, Davies R, Stephens S, Marks S, Chan M, Barkovics M, McLaren CA, Shah V, Dillon MJ, Tullus K (2006) Angioplasty for renovascular hypertension in children: 20-year experience. Pediatrics 118:268-275

8. Vo NJ, Hammelman BD, Racadio JM, Strife CF, Johnson ND, Racadio JM (2006) Anatomic distribution of renal artery stenosis in children: implications for imaging. Pediatr Radiol 36:1032-1036

9. Leiner T, Michaely H (2008) Advances in contrast-enhanced MR angiography of the renal arteries. Magn Reson Imaging Clin $\mathrm{N}$ Am 16:561-572

10. Roebuck DJ (2001) Interventional radiology in children. Imaging $13: 302-320$

11. Coley BD (2004) Pediatric applications of abdominal vascular Doppler: Part II. Pediatr Radiol 34:772-786

12. Brun P, Kchouk H, Mouchet B, Baudouin V, Raynaud A, Loirat C, Azancot-Benisty A (1997) Value of Doppler ultrasound for the diagnosis of renal artery stenosis in children. Pediatr Nephrol 11:27-30

13. Li JC, Wang L, Jiang YX, Dai Q, Cai S, Lv K, Qi ZH (2006) Evaluation of renal artery stenosis with velocity parameters of Doppler sonography. J Ultrasound Med 25:735-742

14. Eklof H, Ahlstrom H, Magnusson A, Andersson LG, Andren B, Hagg A, Bergqvist D, Nyman R (2006) A prospective comparison of duplex ultrasonography, captopril renography, MRA, and CTA in assessing renal artery stenosis. Acta Radiol 47:764-774

15. Conkbayir I, Yucesoy C, Edguer T, Yanik B, Yasar AU, Hekimoglu B (2003) Doppler sonography in renal artery stenosis. An evaluation of intrarenal and extrarenal imaging parameters. Clin Imaging 27:256-260

16. Rountas C, Vlychou M, Vassiou K, Liakopoulos V, Kapsalaki E, Koukoulis G, Fezoulidis IV, Stefanidis I (2007) Imaging modalities for renal artery stenosis in suspected renovascular hypertension: prospective intraindividual comparison of color Doppler US, CT angiography, GD-enhanced MR angiography, and digital substraction angiography. Ren Fail 29:295-302

17. Williams GJ, Macaskill P, Chan SF, Karplus TE, Yung W, Hodson EM, Craig JC (2007) Comparative accuracy of renal duplex sonographic parameters in the diagnosis of renal artery stenosis: paired and unpaired analysis. AJR Am J Roentgenol 188:798-811

18. Grist TM, Thornton FJ (2005) Magnetic resonance angiography in children: technique, indications, and imaging findings. Pediatr Radiol 35:26-39

19. Mendichovszky IA, Marks SD, Simcock CM, Olsen OE (2008) Gadolinium and nephrogenic systemic fibrosis: time to tighten practice. Pediatr Radiol 38:489-496

20. Vasbinder GB, Nelemans PJ, Kessels AG, Kroon AA, de Leeuw PW, van Engelshoven JM (2001) Diagnostic tests for renal artery stenosis in patients suspected of having renovascular hypertension: a meta-analysis. Ann Intern Med 135:401-411

21. Tan KT, van Beek EJ, Brown PW, van Delden OM, Tijssen J, Ramsay LE (2002) Magnetic resonance angiography for the diagnosis of renal artery stenosis: a meta-analysis. Clin Radiol 57:617-624
22. Eklof H, Ahlstrom H, Bostrom A, Bergqvist D, Andren B, Karacagil S, Nyman R (2005) Renal artery stenosis evaluated with 3D-Gd-magnetic resonance angiography using transstenotic pressure gradient as the standard of reference. A multireader study. Acta Radiol 46:802-809

23. Hacklander T, Mertens H, Stattaus J, Lurken M, Lerch H, Altenburg A, Rautenbach J, Cramer BM (2004) Evaluation of renovascular hypertension: comparison of functional MRI and contrast-enhanced MRA with a routinely performed renal scintigraphy and DSA. J Comput Assist Tomogr 28:823-831

24. Stacul F, Gava S, Belgrano M, Cernic S, Pagnan L, Pozzi MF, Cova MA (2008) Renal artery stenosis: comparative evaluation of gadolinium-enhanced MRA and DSA. Radiol Med (Torino) 113:529-546

25. Vasbinder GB, Nelemans PJ, Kessels AG, Kroon AA, Maki JH, Leiner T, Beek FJ, Korst MB, Flobbe K, de Haan MW, van Zwam WH, Postma CT, Hunink MG, de Leeuw PW, van Engelshoven JM, Renal Artery Diagnostic Imaging Study in Hypertension (RADISH) Study Group (2004) Accuracy of computed tomographic angiography and magnetic resonance angiography for diagnosing renal artery stenosis. Ann Intern Med 141:674-682

26. Dellegrottaglie S, Sanz J, Rajagopalan S (2006) Technology insight: clinical role of magnetic resonance angiography in the diagnosis and management of renal artery stenosis. Nat Clin Pract Cardiovasc Med 3:329-338

27. Leiner T, Schoenberg SO (2007) Current status of renal artery magnetic resonance imaging: theoretical and practical considerations and the potential role of blood-pool contrast agents. Eur Radiol Suppl 2:B13-B17

28. Frush DP (2008) Pediatric abdominal CT angiography. Pediatr Radiol 38(Suppl 2):S259-S266

29. Sabharwal R, Vladica P, Coleman P (2007) Multidetector spiral CT renal angiography in the diagnosis of renal artery fibromuscular dysplasia. Eur J Radiol 61:520-527

30. Kim TS, Chung JW, Park JH, Kim SH, Yeon KM, Han MC (1998) Renal artery evaluation: comparison of spiral CT angiography to intra-arterial DSA. J Vasc Interv Radiol 9:553-559

31. Vade A, Agrawal R, Lim-Dunham J, Hartoin D (2002) Utility of computed tomographic renal angiogram in the management of childhood hypertension. Pediatr Nephrol 17:741-747

32. Dondi M (1991) Captopril renal scintigraphy with $99 \mathrm{mTc}-$ mercaptoacetyltriglycine (99mTc-MAG3) for detecting renal artery stenosis. Am J Hypertens 4:737S-740S

33. Fommei E, Ghione S, Hilson AJ, Mezzasalma L, Oei HY, Piepsz A, Volterrani D (1993) Captopril radionuclide test in renovascular hypertension: a European multicentre study. European Multicentre Study Group. Eur J Nucl Med 20:617-623

34. McLean AG, Hilson AJ, Scoble JE, Maher ER, Thakrar DS, Moorhead JF, Sweny P (1992) Screening for renovascular disease with captopril-enhanced renography. Nephrol Dial Transplant 7:211-215

35. Johansson M, Jensen G, Aurell M, Friberg P, Herlitz H, Klingenstierna H, Volkmann R (2000) Evaluation of duplex ultrasound and captopril renography for detection of renovascular hypertension. Kidney Int 58:774-782

36. Minty I, Lythgoe MF, Gordon I (1993) Hypertension in paediatrics: can pre- and post-captopril technetium- $99 \mathrm{~m}$ dimercaptosuccinic acid renal scans exclude renovascular disease? Eur J Nucl Med 20:699-702

37. Ng CS, de Bruyn R, Gordon I (1997) The investigation of renovascular hypertension in children: the accuracy of radioisotopes in detecting renovascular disease. Nucl Med Commun 18:1017-1028

38. Arora P, Kher V, Singhal MK, Kumar P, Gulati S, Baijal SS, Jain S, Kumar A (1997) Renal artery stenosis in aortoarteritis: 
spectrum of disease in children and adults. Kidney Blood Press Res 20:285-289

39. Lagomarsino E, Orellana P, Munoz J, Velasquez C, Cavagnaro F, Valdes F (2004) Captopril scintigraphy in the study of arterial hypertension in pediatrics. Pediatr Nephrol 19:66-70

40. Estepa R, Gallego N, Orte L, Belanger A, Aracil E, Ortuno J (2001) Pediatric renovascular hypertension. Pediatr Nephrol 16:529-531

41. Cheung WS, Wong KN, Wong YC, Ma KM (2004) Segmental renal artery stenosis diagnosed with captopril renography in a child. Pediatr Radiol 34:636-639

42. Soulez G, Therasse E, Qanadli SD, Froment D, Leveille M, Nicolet V, Turpin S, Giroux MF, Guertin MC, Oliva VL (2003) Prediction of clinical response after renal angioplasty: respective value of renal Doppler sonography and scintigraphy. AJR Am J Roentgenol 181:1029-1035

43. McLaren CA, Roebuck DJ (2003) Interventional radiology for renovascular hypertension in children. Tech Vasc Interv Radiol 6:150-157

\section{Answers}

1. c.

2. b.

3. a.

4. b.

5. d. 